\title{
TRADUÇÃO
}

\section{Linhas fundamentais da teoria da faculdade de desejar ${ }^{1}$}

\author{
Karl Leonhard Reinhold
}

É necessário distinguir com precisão, no sujeito representante, entre aquilo pelo qual ele tem de ser pensado como fundamento da mera possibilidade de representação, a faculdade de representação [Vorstellungsvermögen], e aquilo pelo qual ele é o fundamento da representação efetiva e que se chama força representante [vorstellende Kraft]. Por esta força não se pode pensar de modo algum a mera espontaneidade, pela qual, sem receptividade, nenhuma representação chegaria à efetividade e apenas por cujo efeito é produzida somente a mera forma das representações, e o ser-afetado [Afficiertwerden], que é necessário para uma intuição a priori, só é produzido segundo as formas dadas da sensibilidade. Portanto, não se entende aqui por força representante nem a mera espontaneidade nem sua possibilidade segundo formas determinadas a priori da receptividade e da espontaneidade, mas o próprio fundamento da efetividade da representação na medida em que deve estar presente no sujeito representante. Este fundamento do que é efetivo por meio do sujeito representante é determinado e limitado pela forma da faculdade de representação dada a priori, forma que esse sujeito, como ser finito, não pode se dar a si mesmo, e à qual está ligado a priori; e a força representante pode apenas se expressar de acordo com a faculdade que the é dada. A relação da força representante com a possibilidade de representação determinada a priori em sua faculdade, a relação da força com sua faculdade, do fundamento da efetividade com o fundamento de possibilidade da representação, ou com a representabilidade, eu chamo de impulso [Trieb] do sujeito representante, que é composta pela ligação da força com a faculdade e tem de estar presente em todo representante finito, no qual a força se distingue da faculdade. Ser determinado pelo impulso para a

1 „Grundlinien der Theorie des Begerungsvermögens“. In: Versuch einer neuen Theorie des menschlichen Vorstellunsvermögens. Darmstadt: Wissenschaftliche Buchgesellschaft, 1963. Traduzido por Ivanilde Fracalossi (Universidade Federal de São Carlos - UFSCar/PPGFil). Tradução direta do alemão, mas a versão em inglês de Tim Mehigan e Barry Empson, indicada nas referências e única tradução publicada desta obra, foi um importante apoio para comparação e cotejamento. A edição da Wissenschaftliche Buchgesellschaft do Versuch, publicada em Darmstadt em 1963, foi a utilizada na tradução, mas a edição comentada da Felix Meiner, publicada em Hamburg em 2012, também foi consultada, principalmente para atestar correções que apontamos no texto. Nosso profundo agradecimento à Profa. Maria Lúcia Cacciola e ao Prof. Paulo Licht dos Santos pela importante colaboração na tradução, cujas valiosas sugestões contribuíram extraordinariamente para o resultado deste trabalho. Este texto fez parte de uma pesquisa desenvolvida anteriormente com apoio da FAPESP, a quem agradecemos. 
geração de uma representação significa desejo [Begehren)], e a faculdade de ser determinado pelo impulso significa a faculdade de desejar [Begehrungsvermögen] em sentido amplo.

Como a representação em geral é composta por dois componentes essencialmente diferentes e essencialmente ligados, matéria e forma, pode-se então distinguir o impulso para a representação em geral em dois impulsos fundamentais, essencialmente diferentes e essencialmente ligados, o impulso para a matéria e o impulso para a forma da representação. Aquele tem por objeto [Objekt] $]^{2}$ a efetividade do que é dado à representação, este, - o que tem de ser nela produzido. 0 primeiro surge da necessidade [Bedürfnis] fundada no sujeito representante de uma matéria, a qual ele mesmo não pode produzir, ligada à forma, determinada em sua faculdade, da receptividade [Receptivität]; o segundo surge da força positiva presente no sujeito representante, ligada à forma, determinada em sua faculdade, de sua espontaneidade. Um se esforça para o ser-afetado da receptividade e é nessa medida sensível em sentido amplo; o outro se esforça para a expressão da espontaneidade e é, nessa medida, intelectual em sentido amplo. 0 primeiro é satisfeito apenas pelo ser-dado e é nessa medida interessado [eigennützig], o segundo, - apenas por mera ação, e é nessa medida desinteressado [uneigennützig].

0 impulso é chamado sensível no sentido mais estrito enquanto é determinado pelas formas da sensibilidade. $O$ objeto [Objekt] desse impulso é a representação que surge pelo modo de ser-afetado e, decerto, enquanto ela se relaciona com o sujeito representante na consciência, isto é, é sensação. A faculdade de ser determinado pelo impulso para as sensações efetivas eu chamo de faculdade de desejar em sentido mais estrito. Na medida em que uma faculdade sensível referida a seu objeto é intuição, ela pertence à faculdade de conhecimento [Erkenntnissvermögen], não sendo objeto da faculdade de desejar, à qual só pode pertencer em relação ao sujeito. Toda sensação é uma modificação provocada pelo ser-afetado e, portanto, é empírica (mesmo as representações puras do espaço e do tempo são somente representações a priori em relação a seus objetos determinados a priori na faculdade de representação; entretanto, em sua relação com o sujeito, como meras modificações da mente [Gemüt] que surgem por meio do ser-afetado [Afficiertsein] da receptividade segundo suas formas determinadas a priori, elas são sensações e, portanto, empíricas), e o impulso que tem a sensação por objeto tem o empírico por objeto, e se chama, por isso mesmo, impulso empírico.

O impulso sensível, na medida em que se esforça para a sensação externa, pode ser satisfeito apenas pelo ser-afetado de fora, em consideração ao qual o

2 Reinhold diferencia os termos Objekt e Gegenstand. Nesta tradução, indicamos apenas quando o objeto for Objekt, as recorrências mais numerosas e não indicadas referem-se ao objeto como Gegenstand. [Nota da tradutora (N.T.)] 
sujeito representante se comporta apenas passivamente, e a espontaneidade é compelida a agir na produção da forma. Chamo o impulso para a sensação externa de grosseiramente sensível [Grobsinnlichen] para distingui-lo do impulso que tem como objeto apenas a sensação interna, o qual chamo de finamente sensível [feinsinnlich], porque é satisfeito pelo ser-afetado que ocorre por meio da mera espontaneidade; e porque tem por objeto uma sensação na qual a mente não se comporta nem apenas passivamente nem por coerção [gezwungen]. Por essa mesma razão é que o impulso, na medida em que é satisfeito pela ação interna, pode, de fato, ser chamado de interessado, pois sua satisfação é proporcionada pelo ser-dado da matéria, pelo serafetado; mas [ele é] interessado apenas em sentido mais estrito, para se distinguir, também neste aspecto, do impulso grosseiramente sensível, que tem de chamar-se interessado no sentido mais estrito, uma vez que ele só pode ser satisfeito por uma matéria objetiva dada de fora e por algo inteiramente diferente do sujeito e de sua faculdade.

Sensível, em sentido meramente estrito, chamo o impulso enquanto determinado pela sensibilidade em ligação com o entendimento. As modificações que o impulso sensível recebe do entendimento determinante segundo os quatro momentos de sua forma são as seguintes. Segundo a quantidade: impulso para a sensação por meio de uma multiplicidade determinada pelas categorias de unidade, pluralidade e totalidade; para o sensivelmente completo. Segundo a qualidade: impulso para a sensação por meio do ser-afetado determinado segundo as categorias de realidade, negação e limitação, ou contentamento [Vergnügen] conforme o emprego mais forte ou mais leve. Segundo a Relação: 1) impulso para a permanência da subsistência determinável sensivelmente; 2) impulso para a atividade interessada; 3 ) impulso para a sociabilidade interessada. ${ }^{3}$ Segundo a Modalidade: 1$)$ Determinabilidade pelo impulso (predisposição determinada no sujeito representante, forma do desejo); 2) Ser-determinado pelo impulso, desejo efetivo; 3) Desejo efetivo determinado pela forma do desejo, desejo necessário, instinto.

Esse impulso empírico, sensível, interessado e determinado pelo entendimento é chamado racional-sensível, porque sua forma sensível é modificada indiretamente, isto é, por intermédio da sua forma-do-entendimento [Verstandesform], pela forma da razão; a qual estende o impulso interessado, condicionado pela sensibilidade e determinado pelo entendimento, ao incondicionado. 0 caráter ilimitado [Gränzenlosigkeit] da demanda desse impulso relaciona-se com nada além de sensações apenas por intermédio do impulso sensível, determinado pelo entendimento, e excede, nessa medida, toda satisfação possível, que sempre só

\footnotetext{
3 Uma vez que esses três impulsos estão relacionados pelo sentido externo às modificações empíricas deste sentido determinadas na organização, resultam no impulso para a conservação do corpo, para a atividade do mesmo, para o movimento e o impulso sexual [Geschlechtstrieb]. [Nota do autor (N.A.)]
} 
pode ser sensível e, por isso, condicionada. Aqui a razão determina a faculdade de desejar apenas empiricamente, por meio da Ideia do incondicionado, a qual se refere somente aos objetos do impulso sensível determinados pelo entendimento, e constitui a representação de uma totalidade completa desses objetos completamente empíricos. 0 objeto próprio do impulso racional-sensível não é, portanto, nenhuma sensação singular modificada pelo entendimento, mas um estado [Zustand] que surgiria da satisfação de todos os impulsos que são determinados pelo entendimento e estendidos ao absoluto pela razão - a felicidade; um objeto [Objekt] que pode ser representado apenas por meio de uma Ideia em sentido estrito. Eu digo por meio da Ideia em sentido estrito, ou seja, por meio de uma representação do incondicionado, a qual surge apenas através da ligação de conceitos empíricos e na qual a razão é eficaz apenas a posteriori, porquanto o incondicionado, que é essencial à felicidade certamente pensada, surge apenas pela ligação das formas-do-entendimento pelas quais são representados apenas objetos do impulso sensível, objetos da sensação, objetos empíricos. 0 incondicionado, absoluto, completo, ilimitado, que é essencial à felicidade, não é de modo algum objeto imediato do impulso racional-sensível, não é de modo algum desejado em seu próprio nome, desinteressadamente; mas unicamente por causa dos objetos de sensação e de fruição [Genuss] que o impulso racional-sensível se esforça para aproximar-se cada vez mais da Ideia do absoluto. Nessa medida, a felicidade é, de fato, objeto necessário do impulso, mas objeto absolutamente impossível da experiência; o estado do sujeito representante em qualquer momento pode apenas consistir em uma satisfação condicionada ao infinito; e a efetiva felicidade, a possível satisfação do impulso racional-sensível só pode consistir em uma aproximação progressiva infindável do estado efetivo para o ideal de felicidade.

A razão atua no impulso para a felicidade apenas comparativamente [komparativ], mas só é livre na medida em que a forma do incondicionado, conferida pela razão ao impulso, é o efeito da absoluta autoatividade. Porém, o próprio impulso para a felicidade, na medida em que é o resultado da força do sujeito determinada pela sensibilidade, entendimento e razão em conjunto, não é nem livre nem desinteressado. Sua fonte originária é a necessidade de ser afetado modificada pelo entendimento e pela razão; seu objeto imediato é a totalidade incondicionada de sensações determinadas pelo entendimento de acordo com seu objeto, e a sua satisfação depende do ser-dado da matéria objetiva, do ser-afetado de fora; e nessa medida é, pelo menos, tanto um efeito acidental das coisas que o ser representante não tem em seu poder, quanto uma consequência do uso instintivo e racional das habilidades [Fähigkeiten] da força representante. A ciência do objeto desse impulso e dos meios para satisfazê-lo, a doutrina da felicidade, tem de ser extraída tanto da experiência, que não pode se esgotar, quanto das formas da faculdade 
de representação, que podem se esgotar, e o sistema das regras do uso da razão determinado pela Ideia de felicidade, ou a doutrina da prudência [Klugheitslehre], tem de ser distinguido com precisão da moral, com a qual tem tão pouco em comum, quanto a própria doutrina da felicidade.

Já que a razão, no impulso para a felicidade, não tem por objeto senão a ampliação do estado, das sensações determinadas pelo entendimento, que devem ser agradáveis segundo a qualidade, então ela se encontra neste impulso propriamente a serviço da inclinação sensível, da necessária propensão para o contentamento; que a razão determina apenas a posteriori em vista da satisfação desse impulso, e apenas na medida em que este é pressuposto por ela como já efetivo.

A faculdade do sujeito representante de determinar-se pela autoatividade do impulso, ou de determinar-se a si mesmo para uma ação do impulso, é chamada vontade [Wille]; e a efetiva autodeterminação empreendida com consciência para uma ação do impulso é chamada volição [Wollen]. A volição se distingue então do desejo em sentido estrito ou do ser-determinado pelo impulso sensível por ela própria ser um ser-determinado pela razão, uma ação da autoatividade.

A vontade é chamada empírica quando é a faculdade do sujeito para determinar-se a si mesmo para uma ação pensada como um meio da razão para satisfazer o impulso para a felicidade, e é subordinada a essa satisfação como seu fim [Zweck]. Na volição, em uma ação que visa à felicidade, o desejo é determinado pela razão apenas empiricamente, isto é, sob a pressuposição do impulso para o contentamento, ao qual a razão, por meio da ação-da-vontade [Willenshandlung], dá a direção que é determinada na Ideia de felicidade. Assim, a razão age na vontade empírica de modo apenas comparativamente livre, ou seja, apenas na medida em que ela determina o impulso sensível empiricamente e prescreve uma regra para seu modo de ação que recebe a sanção apenas pelo contentamento, por intermédio de um impulso essencialmente distinto da razão.

A Ideia de felicidade, na medida em que é determinada no sujeito representante parcialmente a posteriori pelas sensações, depende, porém, do serafetado de fora e, consequentemente, de circunstâncias externas independentes do sujeito representante; assim, a Ideia de felicidade varia nos diferentes sujeitos representantes e nem mesmo permanece a mesma no mesmo sujeito representante, e tanto a razão como o entendimento, que determinam esta Ideia, certamente, segundo a sua forma, mas apenas de acordo com a matéria dada da sensibilidade, têm de permanecer enganados pelo impulso grosseiramente sensível enquanto a autoatividade só agir a serviço deste, isto é, enquanto a razão determinar a faculdade de desejar apenas empiricamente, conforme os dados [Datis] de uma experiência eternamente incompleta. Somente a razão é capaz de determinar a faculdade de desejar também a priori e, desse modo, antecipar-se aos enganos do impulso 
grosseiramente sensível.

Chamo de puramente-racional o impulso que se determina apenas pela autoatividade da razão e, consequentemente, tem por objeto unicamente o exercício da autoatividade, a mera ação da razão. Esta ação da razão, na medida em que é objeto [Objekt] do impulso puramente-racional, consiste na realização do modo de ação da razão, da forma-da-razão [Vernunftform], que é dada no sujeito apenas segundo a sua possibilidade, mas que, segundo a sua efetividade, só pode ser produzida fora do sujeito pela ação do sujeito. A forma da razão determinada a priori na faculdade é dada ao sujeito e não depende, portanto, da força deste; mas a realização da mesma como forma de uma ação efetiva que não tem outro fim a não ser essa realização mesma, a efetividade da forma da razão como objeto do impulso, é algo que depende da força do sujeito e, decerto, depende apenas da mera autoatividade desta força. A ação da razão no impulso puramente-racional é essencialmente diferente da ação no impulso racional-sensível. Neste, a razão determina apenas a posteriori o representável [Vorstellbar] da sensação, e obtém a matéria de sua ação pela sensação determinada pelo entendimento. No primeiro, ela não opera sob qualquer demanda da sensação, determina a matéria e a forma do seu objeto, opera totalmente independente do ser-afetado, não pressupõe de modo algum o impulso sensível e a faculdade sensível [Empfindungsvermögen] para a efetividade de sua ação e, portanto, age completamente a priori a partir da plenitude de sua autoatividade.

A razão determina o objeto [Objekt] do impulso puramente-racional, a mera realização do modo de ação da razão segundo os quatro momentos do juízo imediato, e o impulso puramente-racional tem de ser pensado de acordo com essas determinações, e opera: segundo a quantidade: como impulso para o modo de ação legítimo [gesetzmässiger] (a forma de ação determinada pela universalidade absoluta), para a realização [Realisierung] da mera legalidade [Gesetzmäßigkeit]; segundo a qualidade: como o impulso para o modo de ação desinteressado (a forma de ação independente da condição sensível da qualidade, do ser dado da matéria e, portanto, do impulso para o contentamento [Vergnügen]), para a realização do desinteresse; segundo a relação: como o impulso para o modo de ação que é: 1) inalterável, 2) autoativo, 3) em harmonia com o modo de ação de todo ser racional; segundo a modalidade: como impulso para o modo de ação que é: 1) permitido, 2) de acordo com o dever, 3) completamente obrigatório.

0 objeto [Objekt] do impulso puramente-racional completamente determinado deste modo chama-se moralidade [Moralität oder Sittlichkeit], que consiste, consequentemente, na pretendida realização do modo de ação da razão pura em seu próprio nome. 0 impulso puramente-racional é chamado moral em relação a este objeto que só a ele é apropriado. 
A razão é chamada prática na medida em que em sua autoatividade se encontra a faculdade para realizar o objeto [Objekt] do impulso puramente-racional ou, em outras palavras, para determinar-se a si mesma a priori para uma ação que não tem outro fim senão a efetividade do modo de ação da razão, e chama-se vontade pura [reine Wille] a faculdade do objeto representante ${ }^{4}$ para determinar-se para a ação através da autoatividade do impulso puramente-racional. Assim, a vontade consiste, em geral, na autodeterminação para uma ação. Se esta ação da razão está subordinada como meio à satisfação do impulso para a felicidade, então a vontade age empiricamente a serviço da sensibilidade; mas se esta ação é determinada pelo objeto [Objekt] do impulso puramente-racional e se, por isso, consiste unicamente na realização intencionada do modo de ação da razão, então a vontade age puramente, opera a priori independentemente do impulso sensível, de acordo com nenhuma outra lei senão a que ela mesma se dá, na medida em que a vontade apenas realiza, por meio de sua autoatividade, a forma determinada da razão, segundo a mera possibilidade desta.

A vontade humana é livre, portanto: 1) na medida em que ela, como faculdade da espontaneidade da razão, não pode ser compelida por nenhum ser-afetado; 2$)^{5}$ na medida em que ela, como faculdade de um sujeito que possui, além de razão também sensibilidade, pode determinar-se tanto a priori quanto a posteriori e, por isso, não está de modo algum exclusivamente vinculada [gebunden] nem à lei dos impulsos desinteressados nem à lei do impulso interessado. Ela age apenas de modo comparativamente livre quando ela própria se submete à lei do impulso interessado, lei que lhe é estranha; em contrapartida, age absolutamente livre e é absolutamente livre na medida em que segue a lei do impulso desinteressado, lei apenas constituída pela razão teórica, mas que recebe sua sanção como lei efetiva somente pela mera autoatividade da razão prática, a qual impõe aquela a si mesma. A moralidade [Sittlichkeit] é impossível sem liberdade absoluta, e a liberdade absoluta é efetiva apenas na sensibilidade ${ }^{6}$ que, na verdade, é necessariamente determinada de acordo

\footnotetext{
4 No texto original está impresso "vorstellenden Objektes". Mas, assim como Alessandro Lazzari, grande intérprete de Reinhold da atualidade, alegamos tratar-se de descuido do autor ou do editor, sendo que "vostellenden Subjektes" deve ser o correto no contexto. Lazzari acusa a passagem como se tratando de um erro desastroso [ominöser Fehler]. (cf. Lazzari. Das Eine, was der Menschheit Noth ist: Luzern - Neapel: Frommann- Holzboog, 2004, p. 154). Já na tradução em inglês mencionada de Mehigan and Empson não há qualquer menção sobre o erro, permanecendo como no original: "representing object" [vorstellenden Objektes]. No entanto, a edição crítica da Felix Meiner já foi publicada com a correção e com uma nota apenas indicando que sujeito é melhor que objeto: (Subjektes] verbessert aus: Objektes). [N.T.].

5 No original, o autor não assinala o item 2. Acrescentamos por suposição, uma vez que não faz sentido elencar apenas um item. [N.T.].

6 No original está grafado sensibilidade, mas outra vez o contexto da discussão nos autoriza a sugerir moralidade. Acreditamos que o autor ou editor tenha se atrapalhado com a semelhança gráfica dos termos "Sittlichkeit" e "Sinnlichkeit". Esta é também a observação de Mehigan e Empson, que optaram por traduzir com a correção, ou seja, moralidade e não sensibilidade, como grafado
} 
com sua forma na forma da faculdade da razão, mas de acordo com sua matéria, ou seja, em relação à realização dessa forma como objeto da vontade, é mero produto da autoatividade, da força positiva, do sujeito que opera livremente [freywirkenden Subjekts].

O impulso para a moralidade é essencialmente diferente do impulso para a felicidade. Um é fundado na mera força positiva, o outro, na mera necessidade modificada pelo entendimento e pela razão; o primeiro é, portanto, completamente desinteressado, o segundo, completamente interessado. Para o primeiro, só a forma possível de seu objeto é determinada na faculdade da razão, a matéria, ao contrário, pela qual seu objeto se torna efetivo, a realização do modo de ação puramenteracional é inteiramente seu próprio trabalho; para o segundo, a matéria de seu objeto é dada pela sensação e, de fato, a matéria objetiva é inteiramente dada pelo ser-afetado de fora. Ela depende, então, em relação à efetividade de seu objeto, de coisas-externas [Aussendingen], e sua forma meramente ideal não alcançável em nenhuma experiência possível, o absoluto da felicidade é a única coisa que, neste impulso, pertence à autoatividade. No impulso para a felicidade, a razão expande as demandas do impulso sensível ao infinito; no impulso para a moralidade, ela não deixa valer nenhuma demanda do impulso sensível, a não ser que esta demanda seja legítima e compatível com a do impulso puramente-racional. Determinado pelo impulso para a felicidade, o sujeito se vê como o centro do universo e relaciona tudo o que é capaz de efetivar pelo entendimento e pela razão ao estado da sua faculdade de sensação, ao contentamento. Determinado pelo impulso para a moralidade, em contrapartida, o sujeito se vê apenas como um membro de uma comunidade que é composta por sujeitos absolutos agindo por meio da razão prática, que não reconhecem nenhum outro fim senão a realização da legalidade, desinteresse etc.

Os dois impulsos estão em contradição direta um com o outro se pensados como coordenados; o impulso para a moralidade é completamente aniquilado quando está subordinado ao impulso para a felicidade, e este, por sua vez, é meramente limitado à legalidade quando está subordinado ao impulso para a moralidade. 0 modo de ação da razão pura, na medida em que é próprio do impulso moral, chamase lei; mas na medida em que é imposto ao impulso para a felicidade, que the é estranho, - chama-se mandamento [Gebot]. A determinação do impulso sensível pela autoatividade do puramente-racional é chamada necessitação [Nöthigung]; e a necessidade [Notwendigkeit] de submeter o impulso sensível à lei do puramenteracional é chamada dever [Pflicht]. Esta necessidade [Notwendigkeit] anuncia-se na consciência por meio do dever [Sollen], que em relação à razão prática é volição livre

no original. Cf. Essay on a new theory of the human capacity for representation, p. 281. A edição crítica da Felix Meiner também publicou corrigida, com apenas uma nota indicando que moralidade é melhor que sensibilidade (Sittlichkeit] verbessert aus: Sinnlichkeit). [N.T.]. 
[frei Wollen] da legalidade, mas em relação à faculdade de desejar é um comando [Gebieten], cujo cumprimento o sujeito que age livremente pela razão prática pode obter de si mesmo apenas por meio da coerção que impõe a seu impulso interessado.

Assim como a sensibilidade e a razão, em sua união inseparável, constituem a natureza da mente humana na medida em que esta é representável, também o impulso para a felicidade e o impulso para a moralidade, em união inseparável, constituem o impulso integral [den ganzen Trieb] da mente humana, e a felicidade ligada à moralidade constitui o integral e completo objeto [Objekt] deste impulso, o bem soberano integral [das ganze höchste Gut] do ser humano. A ligação da felicidade com a moralidade, entretanto, só é pensável por impulso para a felicidade, no sujeito, ser subordinado ao impulso para a moralidade; no objeto [Objekt] ao impulso integral, a medida da felicidade é determinada pela medida da moralidade, e a felicidade só será desejada e alcançada à medida que o sujeito, por sua moralidade, fez-se moralmente capaz, ou seja, fez-se digno [würdig]. Uma vez que a moralidade é a condição unicamente sob a qual a felicidade pode ser objeto do esforço de um sujeito dotado de razão prática, então ela é o soberano, supremo bem. - Mas, porque o sujeito racional finito necessariamente tem de se esforçar para a felicidade, a moralidade somente pode constituir o bem soberano integral desse sujeito em ligação com a felicidade por ela determinada; e o bem soberano integral não pode, por isso, como os epicuristas defendem, nem ser a mera felicidade, em relação à qual a virtude comporta-se como meio para um fim, nem como ensinam os estoicos, ser a mera moralidade (virtude), cuja posse constituiria por si só o bem soberano integral.

Como da determinação mais exata e da execução mais ampla dessas premissas resulta o fundamento-da-crença [Glaubensgrund] para a existência [Dasein] de um mundo inteligível (no qual o bem soberano é alcançável somente pela existência [Existenz] e personalidade do ser racional finito que dure infinitamente) e para a existência [Dasein] de uma causa de toda a natureza que é distinta da natureza e que opera de acordo com a disposição moral [moralischen Gesinnung]: tudo isso só pode ser apresentado de modo suficientemente claro na própria teoria da razão prática, e depois de uma teoria da faculdade de desejar [Begehrungsvermögen] ${ }^{7}$ completamente desenvolvida. A teoria da razão em geral, na medida em que é uma parte da mera teoria do conhecimento [Erkenntnisvermögen] em geral, tem de contentar-se em estabelecer as meras Ideias do mundo inteligível e daquele ser originário na medida em que estas Ideias se fundam na forma da faculdade da razão.

Recebido em: 31.08 .2018 Aceito em: 28.09.2018

7 Que eu tenciono continuar na presente teoria da faculdade de representação [Vosrtellungsvermögen] (N.A.). 